\title{
Dorsolateral striatal lesions impair navigation based on landmark-goal vectors but facilitate spatial learning based on a "cognitive map"
}

\author{
Yutaka Kosaki, ${ }^{1}$ Steven L. Poulter, Joe M. Austen, and Anthony McGregor \\ Department of Psychology, Durham University, Durham DH1 3LE, United Kingdom
}

\begin{abstract}
In three experiments, the nature of the interaction between multiple memory systems in rats solving a variation of a spatial task in the water maze was investigated. Throughout training rats were able to find a submerged platform at a fixed distance and direction from an intramaze landmark by learning a landmark-goal vector. Extramaze cues were also available for standard place learning, or "cognitive mapping," but these cues were valid only within each session, as the position of the platform moved around the pool between sessions together with the intramaze landmark. Animals could therefore learn the position of the platform by taking the consistent vector from the landmark across sessions or by rapidly encoding the new platform position on each session with reference to the extramaze cues. Excitotoxic lesions of the dorsolateral striatum impaired vector-based learning but facilitated cognitive map-based rapid place learning when the extramaze cues were relatively poor (Experiment 1) but not when they were more salient (Experiments 2 and 3). The way the lesion effects interacted with cue availability is consistent with the idea that the memory systems involved in the current navigation task are functionally cooperative yet associatively competitive in nature.
\end{abstract}

There is an increasing body of evidence suggesting that animals, including humans, learn and store information within multiple memory systems in the brain that are predisposed to process specific types of information when faced with the same learning episode (e.g., Packard et al. 1989; Packard and McGaugh 1996; Balleine and Dickinson 1998; Killcross and Coutureau 2003; Yin et al. 2004; Doeller and Burgess 2008). In the spatial learning literature, the neural substrates most frequently implicated in different forms of spatial learning are the hippocampus and the dorsal striatum, with the former being involved in learning with reference to an array of distal cues, a process often referred to as the formation of a "cognitive map" (e.g., O'Keefe and Nadel 1978; Morris et al. 1982), while the dorsal striatum is involved in the formation of an association between a proximal cue in the environment and the animal's own kinesthetic response, typically over many repeated trials (e.g., Packard and McGaugh 1996). Dissociation of these normally cooperating learning systems can be achieved using a task in which the two systems are pitted against each other, producing conflicting behavioral outputs (e.g., Tolman et al. 1947; Blodgett and McCutchan 1948; Packard and McGaugh 1992, 1996).

One classic example of a task with the potential involvement of multiple memory systems is a fixed T-maze discrimination task, in which rats are trained to run from a fixed start arm to a goal location at the end of one of the two goal arms to find food. In this situation, the animals can learn either the goal location with reference to the spatial arrangements of cues surrounding the maze (i.e., place learning), or the specific turning response at the choice point (for example, turn to the left; response learning), or they can learn both; that is, the task can be regarded as a dual-solution task. The content of learning can be assessed by various kinds of probe trials, in one variation of which the entire maze is rotated

\footnotetext{
1Present address: Advanced Research Centres, Keio University, Tokyo, Japan

Corresponding authors: y.kosaki@cantab.net, anthony.mcgregor@ durham.ac.uk

Article is online at http://www.learnmem.org/cgi/doi/10.1101/Im.037077.114.
}

by $180^{\circ}$ so that the animals now start from the position opposite to the location with which they had been originally trained (Tolman et al. 1947). In this probe trial, the memory system concerning the spatial location of the goal and the system based on the specific turning response will lead animals to the opposite arms, thus producing conflicting responses. A number of studies using this and similar methods revealed that the animals can learn based on both strategies, and whether they prefer using one over the other depends on experimental variables such as the availability and nature of extramaze cues and the amount of training (for reviews, see Restle 1957; Packard and Goodman 2013). Neurobiological studies on this T-maze paradigm revealed that the hippocampus is involved in place learning whereas the dorsal striatum or the caudate nucleus is involved in response learning (Packard and McGaugh 1996; Chang and Gold 2003, 2004; Compton 2004; Pych et al. 2005).

Another spatial task in which multiple learning processes may play a role was developed by Pearce et al. (1998) who trained rats in a circular swimming pool to find a platform that was hidden at a consistent direction and distance away from a spherical landmark inside the pool (e.g., the platform always $30 \mathrm{~cm}$ due south of the landmark). In addition to this salient intramaze landmark, there were also various visual cues outside the pool, such as different posters on the walls. Under these conditions, the position of the platform could be identified either by a vector based on distance and direction from the intramaze landmark, or by the array of extramaze cues. Pearce et al. then created a dissociation between the information provided by these two sources by moving the platform and the intramaze landmark together as a unit between sessions, with the effect that the vector from the intramaze landmark served as the only cue that consistently

C 2015 Kosaki et al. This article is distributed exclusively by Cold Spring Harbor Laboratory Press for the first 12 months after the full-issue publication date (see http://learnmem.cshlp.org/site/misc/terms.xhtml). After 12 months, it is available under a Creative Commons License (AttributionNonCommercial 4.0 International), as described at http://creativecommons. org/licenses/by-nc/4.0/. 
predicted the location of the platform across sessions. The extramaze cues were irrelevant at the start of each session, and reliance on them would disrupt the animals' performance, leading them to the incorrect location at which the platform was positioned on the last session. The extramaze cues, however, could benefit the animals' performance for the rest of each session as they maintained a constant relationship to the platform, if rats were able to encode this relationship rather rapidly within a few trials. Pearce et al. (1998) found that the rats with hippocampal lesions were not impaired at learning the vector from the intramaze landmark, but they were critically impaired at encoding the new platform location within each session using the extramaze cues, indicating a selective deficit in "cognitive mapping" (see Roberts and Pearce 1998 for a more detailed analysis of the task).

While the result of Pearce et al. (1998) clearly demonstrates that the hippocampus is responsible for the rapid encoding of place, or cognitive mapping, it is not clear which brain structure is responsible for the alternative solution of the task, namely the one based on the landmark-goal vector strategy. Previous studies that used a similar task found no impairment in vector learning after lesioning the entorhinal cortex (Oswald et al. 2003) or the retrosplenial cortex (Vann and Aggleton 2004). As noted earlier, studies of multiple memory systems in the spatial domain have generally implicated the role of the dorsal striatum (in particular the lateral part of the dorsal striatum) in the alternative, response-type solution (Packard and McGaugh 1992, 1996; Devan and White 1999; Chang and Gold 2004; Compton 2004). The presence of head direction cells in the dorsal striatum (Wiener 1993) also implicates this region as a possible candidate for the vector-based solution of Pearce et al. Moreover, a neuroimaging study in humans highlighted the role of the dorsal striatum in landmark-related navigation in a task similar to that used by Pearce et al. (1998) but in a virtual environment (Doeller et al. 2008). In the study of Doeller et al., participants were asked to learn the locations of several items within a circular boundary with reference both to a landmark inside the boundary and to distal cues outside the boundary (i.e., dualsolution). When participants learned the locations of the items for which the landmark, coupled with directional information provided by the distal cues, served as the only valid cue, they found activation of the right dorsal striatum, whereas learning about items for which the boundary, in conjunction with the distal cues, was the only valid cue activated the right hippocampus (Doeller et al. 2008). Together these findings suggest a potential role of the dorsal striatum in navigation on the basis of a vector from a proximal landmark to the goal.

Accordingly, in the present study we aimed to test the effect of lesions of the dorsolateral striatum (DLS) on vectorbased spatial learning, using a water maze task developed by Pearce et al. (1998). In Experiment 1, rats with either DLS lesions, HPC lesions, or sham lesions were trained to find a submerged plat- form $30 \mathrm{~cm}$ due north or south (counterbalanced across animals) of a spherical landmark inside the pool (Fig. 1; see Materials and Methods for details). The landmark and the platform stayed in the same position during each session of four trials, but they were moved to a novel location at the start of each session. Following the training phase, two probe trials were conducted to assess animals' learning based on the heading vector (landmark test; Fig. 1B) and learning with reference to the extramaze cues (place test; Fig. 1C). In the landmark test, which was the only trial given on the test day, the landmark was placed at a novel location in the pool and the rat's learning about the heading vector from the landmark to the platform was assessed. As there were no preceding trials for the landmark test, performance during the test was expected to be based on the landmark-goal vector acquired through previous training sessions and without the immediate influence of place learning based on extramaze cues. The place test, conducted on the next day after two sessions of retraining, followed three normal training trials with the platform in another novel location. The place test involved removing the landmark and the platform so that the rat's learning solely about the position of the platform with respect to the extramaze cues could be assessed. Experiment 2 assessed further the effect of DLS lesions in vector- and place-based learning, using the same subjects, but in the presence of more salient extramaze cues. As a different
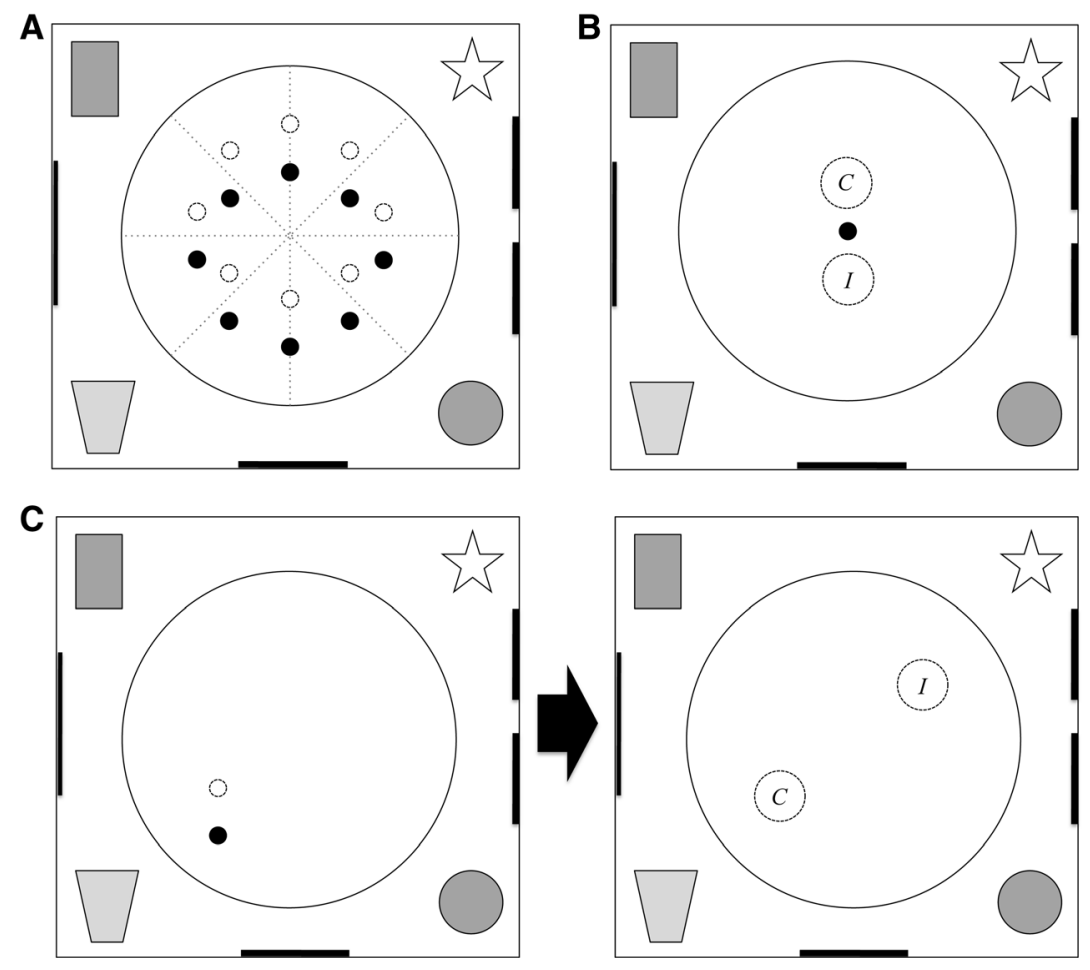

Figure 1. (A) Schematic representation of the water maze and the possible positions that were occupied by the intramaze landmark (black circle) and the hidden platform (dashed circle) in Experiment 1. Various shapes outside the pool represent the extramaze cues (schematic only; not to scale). The same landmark-platform position was used within each session of four trials but for every session a novel position was selected from 16 potential positions (only eight are shown here for ease of exposition). Half of the subjects were trained with the platform $30 \mathrm{~cm}$ due north of the landmark (as shown), while the other half was trained with the platform $30 \mathrm{~cm}$ due south. (B) The design of the landmark test. The landmark was placed at the center of the pool for the first time. The notional correct and incorrect zones $(C, I)$ were set for data analysis with their centers positioned $30 \mathrm{~cm}$ due north or south of the landmark. (C) The design of the place test. The three training trials (on the left panel) were followed by a probe trial (on the right panel) in which the landmark and platform were removed. Notional zones were set at the previous platform location ( $C$; correct) and its diametrically opposite location ( $l$; incorrect). 
pattern of results was obtained in Experiment 2, we conducted Experiment 3 in order to confirm the findings of Experiment 2 using a new cohort of DLS-lesioned animals.

\section{Results}

\section{Experiment 1: effects of DLS and HPC lesions on vector- and cognitive map-based navigation}

We trained three groups of rats with DLS lesions, HPC lesions, or sham lesions in a navigation task which was developed by Pearce et al. (1998) to assess animals' vector- and place-based navigation abilities separately. We predicted that the DLS lesions, but not HPC lesions, would impair navigation based on the landmarkgoal vector, whereas HPC lesions, but not DLS lesions, would impair cognitive map-based navigation.

\section{Histology}

The left and middle columns of Figure 2 represent the reconstruction of the ibotenic acid-induced lesions of HPC and DLS. The HPC lesions resulted in the almost complete loss of cells in the dorsal HPC while some variations were observed with respect to the damage in the ventral HPC. Those rats that exhibited $>40 \%$ damage to the overlying posterior cortical areas (PtA, S1, V2) were excluded from the subsequent behavioral analyses. No damage was observed in any HPC rats to the retrosplenial cortex (RSA and RSG). For the DLS lesions, subjects that sustained extended damage to the cortical areas ventrolateral to the target striatal area (the granular and agranular insular cortices, and the piriform cortex) were excluded from subsequent behavioral analyses. For the remaining DLS animals, the lesions typically resulted in the cell loss in the caudate putamen $(\mathrm{CPu})$ from $2.2 \mathrm{~mm}$ anterior to bregma and $0.8 \mathrm{~mm}$ posterior to bregma, with the damage to the lateral edge of the DLS being most consistent. The damage was typically accompanied by enlargement of the lateral ventricles. The final group size was as follows; Sham, $n=12$; DLS, $n=$ 6 , HPC, $n=6$.

\section{Acquisition}

Figure $3 \mathrm{~A}$ shows the mean escape latencies for the three groups across seven blocks of two sessions. A Lesion $\times$ Block ANOVA revealed a significant effect of block, $F_{(6,126)}=33.13, P<0.001$, and a marginally significant effect of lesion, $F_{(2,21)}=3.37, P=$ 0.054 , as well as Lesion $\times$ Block interaction, $F_{(12,126)}=1.72, P=$ 0.069 . Separate comparisons across lesion groups revealed that Group HPC was slower to find the platform than Sham, $P<0.05$ whereas DLS and Sham did not differ significantly, $P=0.07$. More important, however, on the final block of training, the three groups reached the same asymptote with no difference among groups, $F<1$.

\section{Landmark test}

Following the completion of the training phase, a landmark test was conducted in extinction, with the landmark positioned in the center of the pool for the first time. Figure 3B shows that Sham rats demonstrated a clear discriminative approach to the two zones, set at the correct and diametrically opposite side of the landmark, by entering the correct zone faster than the incorrect zone. In contrast, DLS rats entered the two zones with similar latencies. A Lesion $\times$ Zone ANOVA revealed a significant main effect of lesion, $F_{(2,21)}=5.78, P<0.01$, reflecting that the DLS rats approached the two zones overall more quickly than Sham, $P<$ 0.005 . Planned comparison showed that the Sham rats discriminated the two zones significantly, $F_{(1,21)}=11.11, P<0.005$, but
DLS did not, $F<1, P>0.1$. In addition, we found that DLS entered the incorrect zone significantly faster than Sham did, $P<$ 0.05. Despite the numerical difference, the difference in HPC did not reach statistical significance, $F_{(1,21)}=2.74, P=0.11$.

Figure $3 \mathrm{C}$ shows the amount of time the animals spent in each zone during the landmark test. Consistent with the latency data, Sham rats spent more time in the correct than the incorrect zone, whereas DLS rats again failed to show discrimination between the two zones. In support of this claim, although the Lesion $\times$ Zone interaction failed to reach significance, $F<1$, planned comparisons revealed a significant difference between the correct and incorrect zones in Sham and HPC, $F \mathrm{~s}_{(1,21)}>$ $4.80, P \mathrm{~s}<0.05$, but not in DLS, $F<1, P>0.1$. The results from the landmark test thus showed that DLS-lesioned rats were unable to tell the difference between the correct and incorrect vectors from the intramaze landmark. In contrast, the HPC-lesioned rats showed unimpaired vector-based navigation, consistent with Pearce et al. (1998).

\section{Place test}

Figure 3D shows the result from the place test, during which the landmark, as well as the platform, was removed from the pool and the animals had to rely solely on the information provided by the extramaze cues, had they acquired it in the three preceding training trials. It is clear that only DLS revealed a preference for the correct zone where the platform had been present during the three preceding trials. A Lesion $\times$ Zone ANOVA revealed a significant Lesion $\times$ Zone interaction, $F_{(2,21)}=3.79, P<0.05$. Subsequent analyses showed that the preference for the correct zone was statistically significant in DLS, $F_{(1,21)}=6.76, P<0.05$, but not in Sham rats, $F<1$. Although HPC rats appeared to show a preference for the incorrect zone, these analyses also confirmed their performance did not differ from that expected by chance, $F_{(1,21)}=1.53, P>0.2$. In addition, the simple main effect of lesion was significant for time spent in the correct zone, $F_{(2,21)}=6.0, P<$ 0.01 , with DLS rats spending significantly more time in the correct zone than either Sham, $P<0.05$, or HPC, $P<0.01$. Sham and HPC did not differ significantly, $P>0.05$. Thus, the place test revealed that rats with DLS lesions demonstrated significantly better place performance than sham animals, which, to our surprise, failed to learn the position of the platform with respect to the extramaze cues.

In summary, in Experiment 1, we first replicated the basic findings reported by Pearce et al. (1998) in that HPC lesions did not affect learning based on a landmark-goal vector but impaired rapid encoding of place within each session. Additionally, and perhaps more important, we found that the DLS lesions impaired navigation based on a landmark-goal vector but not navigation based on extramaze cues, confirming our prediction. In fact, DLS animals displayed better place learning than did the control animals, which showed no sign of place learning when tested only with the extramaze cues.

One possible way to account for this pattern of results would be to assume that a learning process which concerns the use of a landmark-goal vector and a learning process which is engaged in place learning based on the extramaze cues were not independent of each other. That is, some form of interaction between these learning processes, similar to overshadowing (Pavlov 1927; Kamin 1969), might have taken place so that learning about the landmark-goal vector in sham animals "overshadowed" place learning based on the extramaze cues, resulting in the poor place performance of sham animals. Learning based on intramaze landmarks has been shown to restrict learning based on extramaze cues in reference memory tasks in the water maze in normal animals (e.g., Redhead et al. 1997; Roberts and Pearce 1998, 1999), 

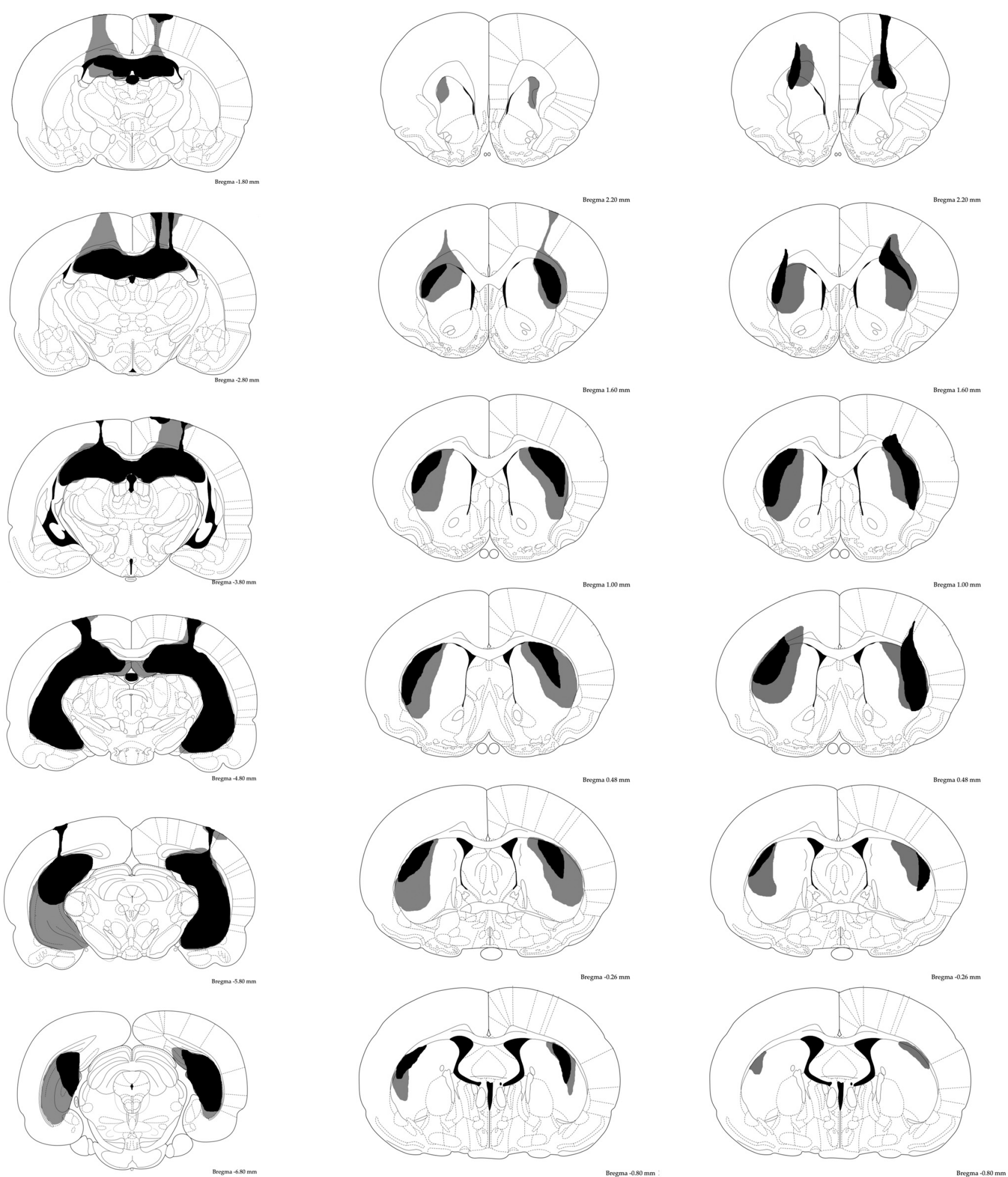

Figure 2. Schematic representation of ibotenic acid lesions of HPC for Experiment 1 (left), DLS lesions for Experiments 1 and 2 (middle), and DLS lesions for Experiment 3 (right). The extent of damage from subjects bearing the maximum and minimum volume of damage in each group is represented in light gray and black, respectively. Atlas plates are adapted from Paxinos and Watson (1998).

and it seems reasonable to assume a similar competition process at work in the current task, although the intramaze landmark was used to derive a vector to the platform rather than for direct beacon homing as in the previous studies. On the other hand, the fail- ure of HPC rats to discriminate correct from incorrect locations in the place test was most likely not for the same reasons as for the Shams. Instead, for these animals their failure to learn based on the extramaze cues was likely to be due to the well-documented 

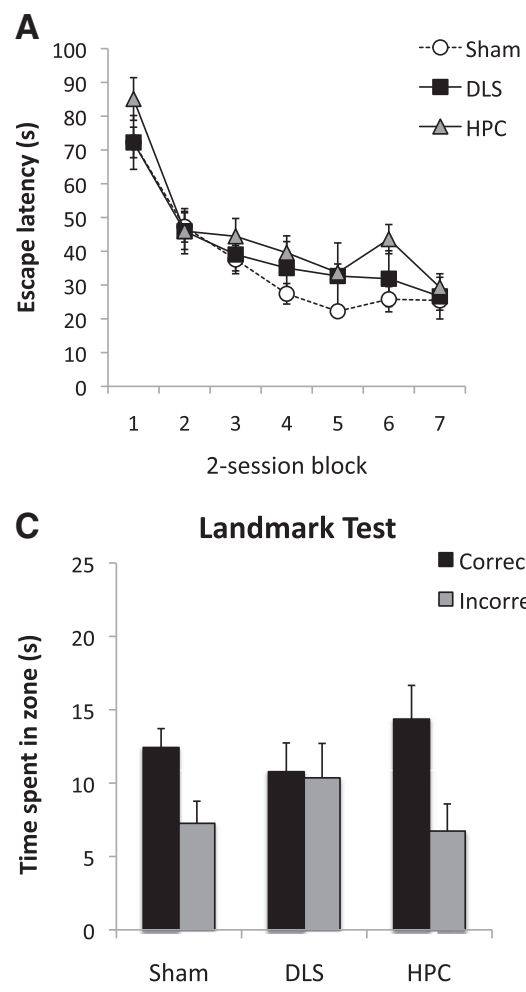

Figure 3. Behavioral results from Experiment 1. $(A)$ The mean escape latency across 14 sessions of training, shown in two-session blocks. $(B)$ The mean latencies to enter the correct and the incorrect zones during the landmark test. (C) The mean times spent in the correct and the incorrect zones during the landmark test. $(D)$ The mean times spent in the correct and the incorrect zones during the place test. Error bars represent \pm SEM.

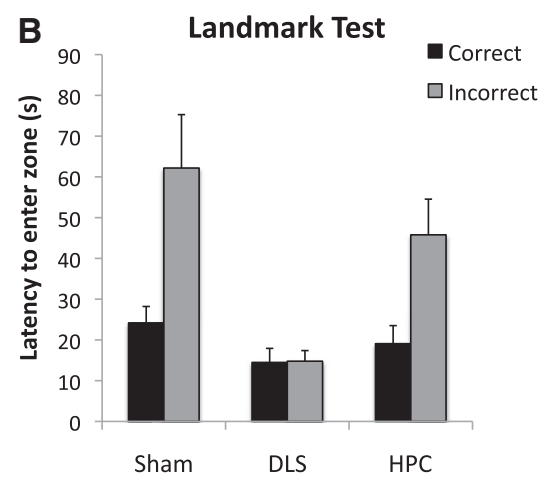

D

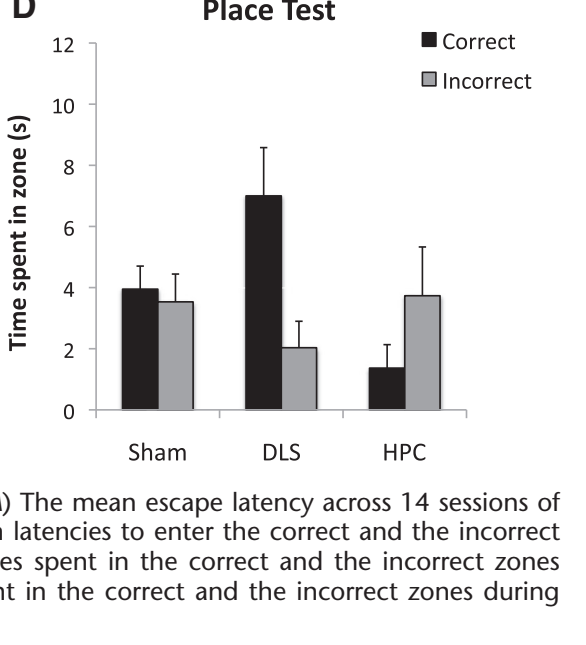

sion was increased to six, as another attempt to make Sham animals rely more on the place cues, as this manipulation should increase the validity of extramaze cues in relation to the vector cue within each session.

We predicted that these manipulations would reduce the degree to which the landmark-goal vector overshadowed place learning in Sham animals, which would then reduce the facilitatory effect of DLS lesions on place learning. On the other hand, rich extramaze cues might also have an impact on the vector-based navigation in DLS animals, as it has been previously demonstrated that inactivation of the DLS impaired a response version of plus maze task only when the extramaze cues were impoverished but not when the cues were rich (Chang and Gold 2004). Thus, making the extramaze cues more salient might alleviate the DLS lesion-induced impairment in landmark-goal vector learning. Rendering the extramaze cues more salient was achieved by adding several salient objects around the pool and also by replacing some inconspicuous stimuli on the wall with more salient ones (see Materials and Methods for more details). The experiment started $\sim 6 \mathrm{wk}$ after the completion of Experiment 1, using the same Sham and DLS groups used in Experiment 1 . dependence of place learning on a functioning hippocampus (e.g., Morris et al. 1982; Pearce et al. 1998). At the same time, the lesion-induced absence of vector learning in DLS animals would fortuitously have saved these animals from the overshadowing effect and hence they displayed a better place performance than Shams.

In conditioning, the degree of overshadowing has been shown to depend upon, among other variables, the relative salience of competing cues (Mackintosh 1976; Kosaki et al. 2013), which suggests that one way to test the above hypothesis is to change their relative salience. More specifically, we predicted that if the extramaze cues were made more salient, then it would be more difficult for vector learning to overshadow place learning based on these cues, which should then result in sham animals displaying a similar level of place performance as DLS animals. If, on the contrary, the facilitation of place learning after DLS lesions was caused by some other mechanism, then changing the salience of extramaze cues, or indeed any manipulation that results in a reduction of an overshadowing effect on Sham animals, should not affect the extent of facilitation seen in DLS animals. Thus, the purpose of Experiment 2 was to test the effect of changing the salience of the extramaze cues.

\section{Experiment 2: effects of DLS lesions on vector- and cognitive map-based navigations under enriched extramaze cues}

In Experiment 2, we retrained the same Sham and DLS rats used in Experiment 1 in the same water maze task but using more salient extramaze cues. In addition, the number of trials within each ses-

\section{Acquisition}

The escape latency was relatively short from the beginning of training (Fig. 4A), suggesting the presence of a positive transfer from Experiment 1 . A Lesion $\times$ Session ANOVA showed no significant effect of session, $F_{(5,65)}=1.47, P>0.1$, lesion, $F<1$, or Lesion $\times$ Session interaction, $F<1$.

\section{Landmark test}

Figure 4B shows the latency to first enter the correct and incorrect zone during the landmark test. There was a significant effect of zone, $F_{(1,13)}=10.40, \quad P<0.01$, but the effect of lesion or Lesion $\times$ Zone interaction was not significant, $F \mathrm{~s}<1$. Figure $4 \mathrm{C}$ shows the search time in each zone during the landmark test. The overall effect of zone was significant, $F_{(1,13)}=34.81, P<$ 0.001 , but the effect of lesion or Lesion $\times$ Zone interaction was again not significant, $F \mathrm{~s}<1$, The results thus confirm that, unlike Experiment 1, there was no effect of DLS lesions on navigation based on the landmark-goal vector under the rich extramaze cues condition.

\section{Place test}

Figure 4D shows the result from the place test. There was a significant effect of zone, $F_{(1,13)}=23.15, P<0.001$, but despite a slight numerical difference between the groups in the time spent in the correct zone the effect of lesion or Lesion $\times$ Zone interaction was not significant, $F \mathrm{~s}_{(1,13)}<2.08, P \mathrm{~s}>0.1$. The result suggests that both Sham and DLS animals showed a significant preference for the previously reinforced place solely on the basis of the rich extramaze cues. 
A
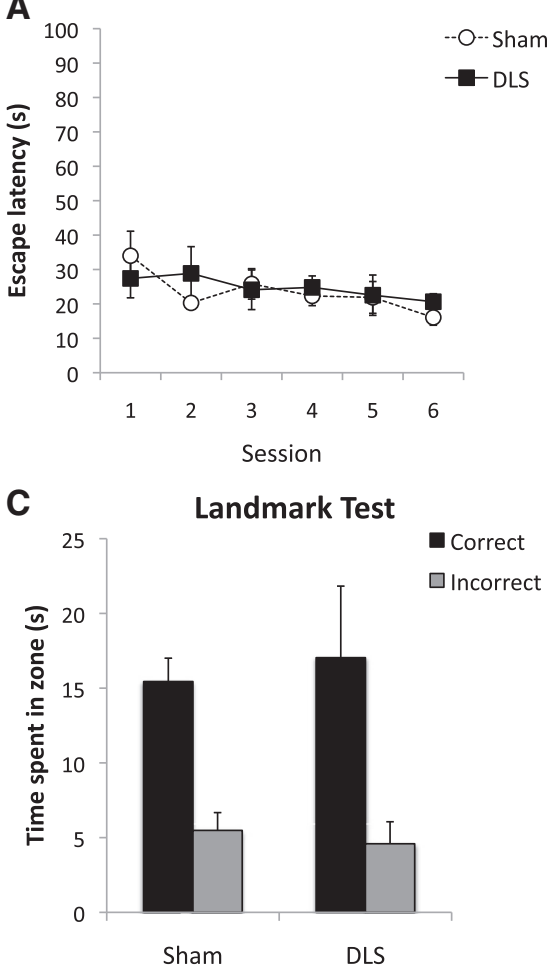

B

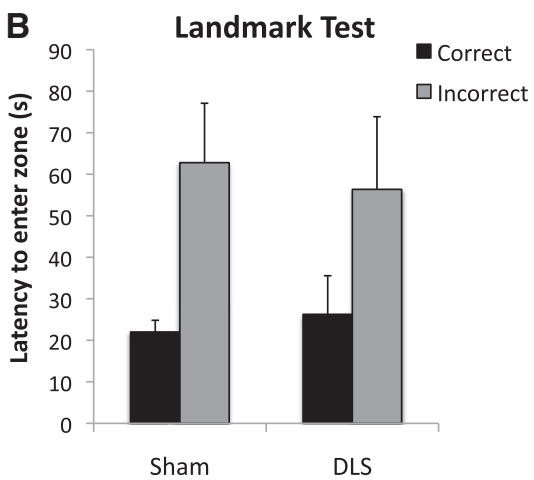

D

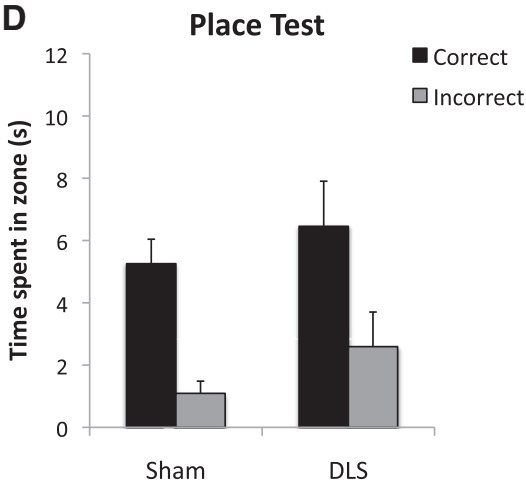

Figure 4. Behavioral results from Experiment 2. (A) The mean escape latency across six sessions of training. $(B)$ The mean latencies to enter the correct and the incorrect zones during the landmark test. (C) The mean times spent in the correct and the incorrect zones during the landmark test. (D) The mean times spent in the correct and the incorrect zones during the place test. Error bars represent \pm SEM.

In summary, Experiment 2 revealed that both of the effects observed in Experiment 1, namely the facilitation of place learning and impairment of vector-based learning after DLS lesions, disappeared when the extramaze cues were made more salient. This pattern of results is entirely consistent with the hypothesis we developed in the discussion of the last experiment. Before going into further discussion, however, we must consider one alternative account that the result in the current experiment is produced by nothing but the repeated training and testing administered for the same animals used in Experiment 1. Thus, it might be possible that any further training after Experiment 1, regardless of the salience of the extramaze cues, could have resulted in the improvement of performance in place and landmark test in Sham and DLS animals, respectively.

In order to rule out this possibility, we conducted Experiment 3 using a new cohort of DLS and Sham animals, and trained them under the rich extramaze cues as described for Experiment 2. The number of trials within each session was changed back to four to enable a direct comparison between Experiments 1 and 3. One further change in Experiment 3 was to alter the direction of the correct landmark-goal vector so it was along the eastwest axis, rather than north-south as was used in Experiments 1 and 2. This was to rule out the possibility that improved performance in the place test in Experiment 2 was due to the rats' use of a simple piloting strategy. That is, the inclusion of the salient black wallpaper on the north wall potentially could have enabled the rats to approach one side of the pool more than the other, meaning time spent in the correct location would be artificially inflated in the place test by use of an alternative strategy. By altering the orientation of the correct vector in Experiment 3 this possibility was ruled out.
Experiment 3: effect of DLS lesions on vector- and cognitive map-based navigation under the enriched extramaze cues in naïve animals

\section{Histology}

The right-hand column of Figure 2 shows the extent of lesions observed for the DLS rats in Experiment 3. Two DLS rats that sustained extended damage to the cortical areas ventrolateral to the target striatal area (the granular and agranular insular cortices, and the piriform cortex) were excluded from subsequent behavioral analyses. For the remaining DLS animals, the extent and location of lesions were similar to those observed for the animals in Experiments 1 and 2. The final group size was as follows: Sham, $n=11$; DLS, $n=10$.

\section{Acquisition}

Figure $5 \mathrm{~A}$ shows the mean escape latencies for the lesion and control groups across 12 sessions of training. Sham rats acquired the task slightly faster than the DLS rats early in training but the two groups eventually reached a similar asymptote. Lesion $\times$ Block ANOVA revealed a significant effect of block, $F_{(5,95)}=46.05, P<0.001$, but there was no effect of lesion, $F_{(1,19)}<1$. The Lesion $\times$ Block interaction approached significance, $F_{(5,95)}=2.27, \quad P<0.1$, and subsequent analysis showed that Sham performed faster than DLS only on the second block, $P<0.01$.

\section{Landmark test}

The results from the landmark test are shown in Figure 5B,C. Inspection of the figure suggests that on average both groups entered the correct zone first, but overall the preference was rather modest. Consistent with this observation, a Lesion $\times$ Zone ANOVA failed to reveal a significant main effect of zone, $F_{(1,19)}=2.81, P>0.1$. There was neither a main effect of lesion, $F_{(1,19)}=2.41, P>0.1$, nor an interaction, $F_{(1,19)}<1$. Clearer evidence of vector-based navigation, however, was found with the search time measure, shown in Figure 5C. The figure shows that the rats spent more time in the correct zone than in the incorrect zone during the landmark test. A Lesion $\times$ Zone ANOVA revealed a significant effect of zone, $F_{(1,19)}=8.03, P<0.05$, reflecting the overall preference for the correct zone. There was no effect of lesion or a Lesion $\times$ Zone interaction, $F \mathrm{~s}<1$. Thus the results of the landmark test suggest that DLS lesions had no effect on discrimination between the correct and incorrect vectors from an intramaze landmark when the more salient extramaze cues were used, confirming the finding of Experiment 2.

\section{Place test}

Figure 5D shows the result from the place test. Both groups successfully identified the location where the platform had been present during the preceding trials. A Lesion $\times$ Zone ANOVA revealed a significant effect of zone, $F_{(1,19)}=11.15, P<0.01$, but the Lesion $\times$ Zone interaction was not significant, $F<1$. Thus, the 
A
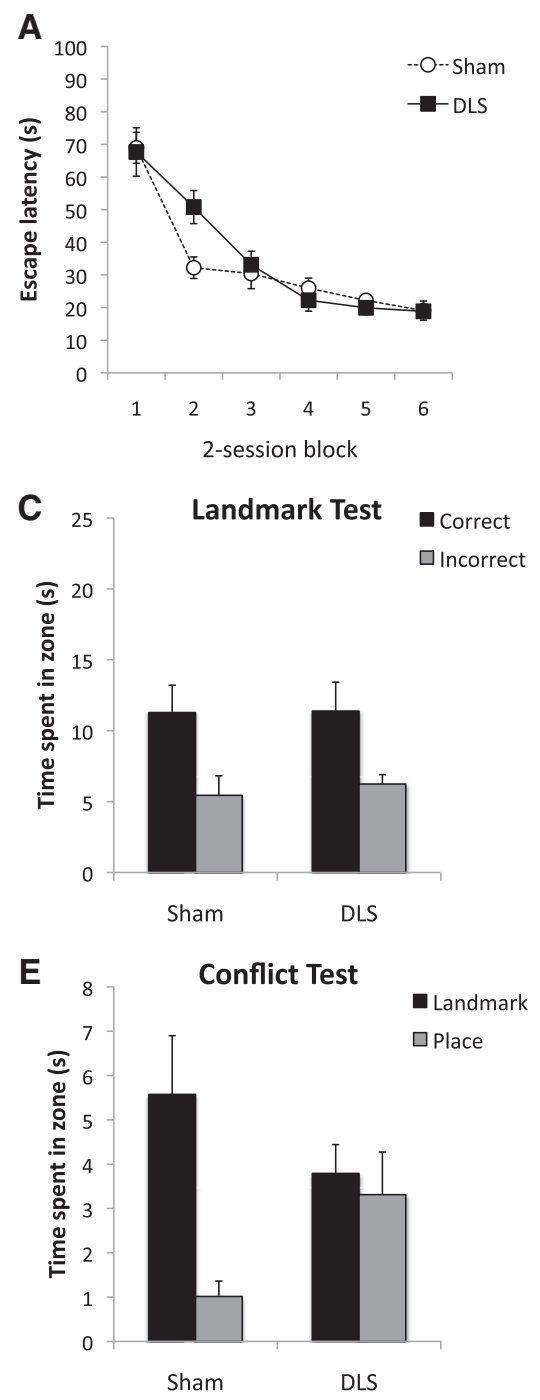

Figure 5. Behavioral results from Experiment 3. $(A)$ The mean escape latency across 12 sessions of training, shown in two-session blocks. $(B)$ The mean latencies to enter the correct and the incorrect zones during the landmark test. (C) The mean times spent in the correct and the incorrect zones during the landmark test. $(D)$ The mean times spent in the correct and the incorrect zones during the place test. $(E)$ The mean times spent in the "landmark" zone and the "place" zone during the conflict test. Error bars represent \pm SEM.

place test showed that, unlike Experiment 1, both groups of animals were equally able to identify the previous location of the platform solely on the basis of information provided by the extramaze cues.

\section{Conflict test}

To ensure that the null results found so far in the current experiment are not due to insufficient lesions of the DLS, we conducted a further test on the final day of the experiment. Following three normal training trials, the rats received a conflict test, in which the landmark was moved to a new location which was diametrically opposite from where the landmark had been present during the three preceding trials. Figure 5E shows that Sham rats demonstrated a clear preference for the zone signaled by the correct vector from the current position of the landmark ("landmark" zone) and hardly spent any time in the zone in which the platform had been positioned during the last three trials ("place" zone). In conbias toward sampling the previous platform location first before swimming to the visible platform in the new location. While the two studies are different in many aspects including the use of vector-based learning in the current study rather than direct navigation to the visible platform, the results still bear a striking similarity in that DLS lesions facilitate the use of place cues in a conflict situation.

\section{Effectiveness of cue manipulation}

Finally, in order to assess the effectiveness of the cue manipulation made to the extramaze cues, we compared the amount of learning that took place within each session of four trials in Experiment 1 with Experiment 3. Within-session learning was measured by comparing the latency to find the platform on trial 1 and on trial 4 of each session, across the last five sessions of training, during which the overall performance was stable. The index of within-session learning was used in a previous study for a 
measure of cognitive map-based rapid place learning (Pearce et al. 1998). Figure 6 shows the mean difference in latencies between the first and the last trial of each session for Sham and DLS groups. A two-way ANOVA with between-subjects variables of experiment (Experiment 1 versus 3 ) and lesion revealed a significant main effect of experiment, $F_{(1,35)}=9.77, P<0.005$, with animals displaying greater difference between the first and the last trial in Experiment 3, which confirms that the cue manipulation made for Experiment 3 (thus for Experiment 2 as well) was successful in increasing the amount of place learning taking place rapidly within each session. Moreover, there was a marginally significant Experiment $\times$ Lesion interaction, $F_{(1,35)}=3.90, P=0.056$. The subsequent simple main effect analyses on the interaction revealed that the difference between Experiments 1 and 3 was significant in Sham, $F_{(1,35)}=16.46, P<0.001$, but not DLS, $F<1$, which further supports the interpretation that the place learning in Experiment 1 was overshadowed by landmark-goal vector learning in Sham, but not DLS, and that the cue manipulation in Experiment 3 removed this effect in the former but did not affect place performance in the latter.

Some comment is required regarding the seemingly differential effect of cue manipulation upon place and vector learning in Sham and DLS groups, respectively. It is possible, for at least two reasons, that the change to the extramaze cues affected place learning more directly, and thus to a greater extent, than the use of those cues used to determine direction. First, it could be because aspects of the extramaze stimuli used for direction were different from those used for place learning. For example, animals might have extracted directional sense by using those aspects of the extramaze stimuli that were not changed by the cue manipulation, such as static sound, smell, or geometry of the experimental room. Second, while the extramaze cues are required for both landmark and place strategies, crucially it may be argued that they are required to different degrees. While the landmark strategy uses both the extramaze and the intramaze cues, the place strategy has to rely solely on the extramaze cues. Therefore, it seems natural that the manipulation of the extramaze cues affected one strategy more than the other. More specifically, making the extramaze cues more salient should aid the place strategy more than the vector strategy. This would explain why Sham animals improved their place performance but did not improve much on vector learning as a result of the cue manipulation. On the other hand, it seems more difficult to explain why the same cue manipulation improved DLS's directional learning without significantly enhancing their place learning. Empirical evidence suggests that the effect of disrupting the DLS function on a response task is apparent only when the place cues are scarcely available (Chang and

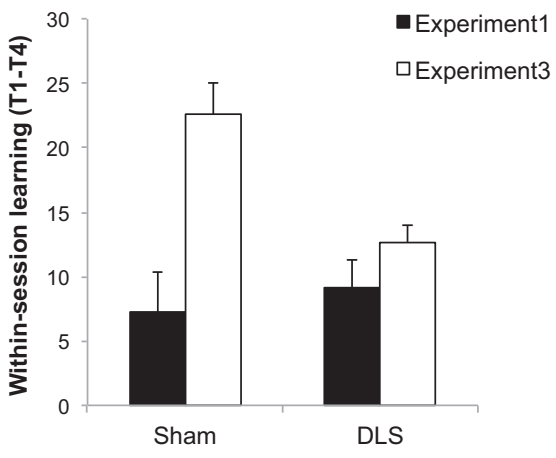

Figure 6. Within-session learning measured by the differences in latencies to find the platform on the first and the last trial of each session in Experiments 1 and 3, split by lesion group. Error bars represent +SEM.
Gold 2004). It has been further suggested that with salient place cues, the rats could solve the response task as a complex place task, which is conditional upon the start position (e.g., from place A, go to place $\mathrm{X}$, while from $\mathrm{B}$ go to $\mathrm{Y}$, without using any response strategy). Thus, it is possible that in the current task the DLS animals were able to use some form of place strategy to figure out the direction of the platform from the intramaze landmark. Indeed, there is some support for this claim, which can be found in Figure 5B,C. In Experiment 3, where place cues were enriched, the landmark test revealed that the initial discrimination of correct from incorrect zones was overall nonsignificant (Fig. 5B). Only if the vector performance was measured by the search time in the subsequent test period, did we find evidence of reliable directional learning in the two groups (Fig. 5C). Thus, not only DLS, but Sham animals as well, might have been using their enhanced place strategy during the landmark test in Experiment 3 . That is, overshadowing was reciprocal so that with rich place cues the place learning overshadowed vector learning. While the account is interesting, however, it is only speculative until we are able to identify the aspects of the extramaze stimuli that were used by animals for directional navigation so that we can directly manipulate the salience of directional cue just as we did for the place cues. Whatever the precise mechanism for the improved vector performance in DLS after the cue manipulation, overall, the analysis of within-session learning offers further support for the claim that the extramaze cues were rendered more salient in Experiment 3. This finding endorses our interpretation of the results that the manipulation led to the removal of the overshadowing of place learning in Sham animals and the concomitant facilitation effect on DLS animals.

To summarize, Experiment 3 showed that there was no clear evidence that DLS lesions impaired vector-based navigation when the more salient extramaze cues were used. At the same time, Sham rats showed clear evidence of cognitive map-based place learning at a level comparable with that in DLS rats. These results thus replicate what we found in Experiment 2, and exclude the possibility that the difference between Experiments 1 and 2 was caused by repeated administration of training and testing in the second experiment or the increased number of trials within each session. Rather, the difference was more likely to be produced by the different salience of extramaze cues, a point supported by the between-experiments analysis just presented.

Together, these results indicate that whether DLS lesions impair vector-based navigation or not critically depend on the salience of extramaze cues, a finding consistent with a previous report of cue-dependency of DLS-inactivation effect on a different type of response task (Chang and Gold 2004). Furthermore, the variation in the cue salience was also correlated with the presence or absence of place learning in Sham animals, which in turn determined the presence of facilitation of place learning in the DLS-lesioned animals. These findings will be discussed in further details below.

\section{Discussion}

The three experiments reported here explored the role of the DLS in navigation based on a vector from a proximal landmark inside a bounded arena. The DLS lesions impaired vector-based navigation in Experiment 1 as evidenced by their lack of discrimination during the landmark test. When the extramaze cues surrounding the water maze were made more salient in the subsequent two experiments, however, the DLS lesions no longer impaired vector-based navigation. This cue-dependent effect of DLS lesions is consistent with a previous demonstration that inactivation of the DLS impaired a response version of the plus-maze task only when the 
extramaze cues were minimal (Chang and Gold 2004). It has been previously suggested that with rich extramaze cues, rats could acquire the response task by virtue of an alternative strategy, such as learning places conditionally upon different start locations (Blodgett and McCutchan 1947, McNamara et al. 1956), which could mask the effect of DLS lesions on the response learning system (Chang and Gold 2004; Pych et al. 2005).

Interestingly, this cue-dependent deficit in vector learning was mirrored in the cue-dependent facilitation of place learning after DLS lesions. Thus, when the extramaze cues were relatively poorer, the control animals failed to show place learning, which led to DLS-lesioned animals performing better at the place test (Experiment 1). DLS lesions did not facilitate place learning when the extramaze cues were of higher salience (Experiments 2 and 3), although the DLS lesions still resulted in a bias toward more reliance on the place cues as compared with Sham when the place and vector cues were directly pitted against each other in a conflict test in Experiment 3 (see also Devan and White 1999).

Taken together, these findings suggest two important conclusions. First, while the DLS is critically involved in vector-based learning, whether the lesion effect emerges or not depends on the availability of extramaze cues. Second, the vector- and place-based solutions are in competition with each other for the strength of learning, such that vector-based learning overshadows placebased learning when the place cues are less salient but not when they are more salient, in accordance with the basic principles of learning described by associative learning theories (e.g., Rescorla and Wagner 1972; Mackintosh 1975; Pearce and Hall 1980). This cue competition, or more precisely the lack of cue competition, resulted in the DLS-lesioned animals showing better place learning than the control animals in Experiment 1, where the controls completely failed to reveal place learning.

The current set of results thus provides a demonstration that place learning with reference to an array of distal cues can be subject to competition by striatal-dependent response-type learning, in this case vector-based learning, and that removal of vector learning facilitates place learning. For the clarity of the argument, let us stress that it is important to make a distinction between a task in which the two strategies, or two learning systems, produce competing or incongruent behavioral outputs (e.g., singlesolution plus maze such as the place- or response-only version of the task), and a task in which the two systems produce a congruent output (e.g., dual-solution plus maze). If the task predisposes two systems to compete with each other, by producing conflicting behavioral outputs (i.e., performance based on each memory system being incongruent), the disruption of one system should naturally lead to a facilitation of the other, and indeed there are a number of such demonstrations of facilitation in "singlesolution" maze experiments after disruption of the neural substrate for the alternative, irrelevant solution (Mitchell and Hall 1988; Packard et al. 1989; McDonald and White 1993; Chang and Gold 2003; Compton 2004; Lee et al. 2008). A bias in a conflict test toward reliance on a particular strategy after compromising the ability to use the alternative strategy is another example of this type of competition (e.g., the conflict test in Experiment 3 of the current study; Packard and McGaugh 1996; Devan and White 1999; Kim et al. 2001; Schwabe et al. 2008). However, it is a different question regarding the nature of the interaction of memory systems in "dual-solution" tasks. The question then is whether the strength of learning based on one system is affected by the concurrent presence of another system that produces the "same" prediction about the goal and hence same behavioral output. That is, does competition between systems occur at the level of learning, when the systems are working in parallel to produce the same behavioral performance? The nature of this type of interaction can be best described using the concept of well-studied as- sociative competition termed overshadowing (Pavlov 1927; Kamin 1969). Overshadowing is said to occur if conditioning to a stimulus $\mathrm{A}$ progresses faster when $\mathrm{A}$ is presented alone during training (A-US) than when $\mathrm{A}$ is presented in conjunction with another stimulus, X (AX-US), and the effect has been consistently found in a wide variety of learning paradigms including spatial learning tasks (e.g., Diez-Chamizo et al. 1985; Pearce et al. 2006; Horne et al. 2010; Kosaki et al. 2013; for review, see Pearce 2009). With the difference in mind, let us clarify the nature of the interaction involved in the current task. While landmark-goal vector learning in the current task could have been hindered by the concurrent presence of an incongruent place learning system on the first trial of every session (i.e., competition for behavioral output), which therefore defines the vector learning as a partially "single-solution" process, place learning within each session was always alongside vector-based learning, which therefore makes the place learning a "dual-solution" process. The current study is unique in that the facilitation of place learning after DLS lesions was observed even when the concurrently available vector solution was cooperative in nature (i.e., both indicated the same location) and thus produced the same behavioral output as that produced by the place learning. Consequently, the present finding of facilitation cannot be explained by the same mechanism that explains the facilitation of a single-solution task, in terms of competition at the level of performance. Instead, our results can be best explained by assuming the presence of cooperative yet associatively competitive learning systems. To our knowledge, this is the first demonstration of facilitation of this kind in spatial learning following damage to a certain neural substrate of one type of learning system.

A possible objection to the above argument may be made based on the series of influential suggestions that some forms of hippocampal-dependent learning are only incidental and impervious to other forms of learning (O'Keefe and Nadel 1978; Cheng 1986; Gallistel 1990; Doeller and Burgess 2008). Doeller and Burgess (2008; see also Doeller et al. 2008), for instance, stated that learning locations relative to a boundary coupled with distal cues is incidental and impervious to learning locations relative to an intramaze landmark, based on their finding that the latter did not overshadow the former learning in human subjects. In the current study, learning based on distal cues coupled with the pool boundary suffered from a competition from learning based on the vector from the intramaze landmark, but only when those distal cues were made less salient. Thus, as is often the case in the demonstration of cue competition in spatial domain (e.g., Chamizo et al. 2006; Horne and Pearce 2011; Kosaki et al. 2013), we observed this competition effect depending on the relative salience of each cue, in a manner consistent with findings in a wider range of conditioning literature (Pavlov 1927; Miles and Jenkins 1973; Mackintosh 1976). ${ }^{2}$ Support for the foregoing argument, based on associative competition between learning systems, is offered by Gibson and Shettleworth (2005), who trained rats on a dual-solution (place- and response-effective) radial maze task. They found that the strength of place learning alone was weaker after place + response training if the same response had previously been trained in the absence of place cues, than if a different response had been previously learned. That is, they demonstrated, using a blocking paradigm (Kamin 1969), that

\footnotetext{
${ }^{2}$ As a related issue, it should be noted that in the current experiments the landmark-goal vector was a relevant source of information throughout the experiment, whereas the place cues were relevant only within each session, and even irrelevant on the first trial of each session. Therefore, the task was designed particularly in favor of the vector learning, which should also have contributed to the overshadowing of place cues through a relative validity effect (Wagner et al. 1968; Kosaki et al. 2013).
} 
place learning can be subject to cue competition from the alternative response learning (Gibson and Shettleworth 2005; but see White 2005 for an alternative account).

While the argument presented so far can explain the current set of results well, it is still important to ask whether the facilitation of place learning produced by the DLS lesions could be produced by any means other than associative competition between multiple learning strategies. One possibility is that the facilitatory effect of DLS lesions was a general effect upon the overall function of the hippocampus, independent of the indirect effect via the removal of associative competition. For example, Poldrack et al. (2001) tested human participants using fMRI while they performed one of two classification tasks. Although they were rather different from the spatial tasks described here they nonetheless engaged the same memory systems that are the focus of this study. When the task activated one system activity in the other decreased, which is suggestive of competition for the engagement of the different systems. However, in another human imaging study mentioned above, in which participants were engaged in a dual solution navigation task modeled on the one we used here, no direct modulation of neural activity between the hippocampus and the caudate nucleus was found, which would be expected if these structures had reciprocal inhibitory influences (Doeller et al. 2008). This result implies that the facilitation of place processing after DLS lesions found in the current study is not necessarily due to direct enhancement or disinhibition of hippocampal neural activity in general, but rather an indirect effect mediated by the absence of the overshadowing of place learning by vector learning, such that associative competition at the behavioral level has been removed. The fact that the facilitation was not observed in DLS rats under circumstances in which no competition was observed in Sham animals, i.e., Experiments 2 and 3, supports the latter conclusion.

Finally, the landmark-goal vector learning in the current task can be considered to be a variant of "directional" spatial navigation studied previously (Blodgett et al. 1949; Skinner et al. 2003; Hamilton et al. 2007, 2008, 2009). In a series of experiments, for instance, Hamilton et al. trained rats in the water maze to find a platform in a consistent position, and after acquisition they moved the entire pool to a new position within the experimental room. This shift created a conflict whereby the previous platform location was now positioned at the opposite side of the pool in terms of the direction from the center of the pool, but the position was unchanged with respect to the absolute coordinates within the room. Thus, the shift was designed to dissociate animals' use of directional navigation and "true" ' place navigation under a conflict situation. Although the experiment was not intended to test directional and place navigation separately, so it is not known whether the two strategies interacted during learning as we found in the present study, the result of their conflict test is still relevant to the current argument. During the conflict test rats showed a significant preference for the learned direction and hardly spent any more time in the learned place than expected by chance (Hamilton et al. 2007, 2008). Only if the wall of the pool was minimized as a cue by filling the water to near the top of the pool was significant control by room cues with reference to place navigation observed, so that animals displayed "true" place navigation in the conflict test (Experiment 6, Hamilton et al. 2008) - but the preference was only transient and soon replaced by preference for directional navigation with continued training (Hamilton et al. 2009). Taken together these results bear two important implications for the current study. First, in an aversively motivated situation at least, a directional navigation strategy, controlled by directional information derived from distal cues and distance information derived from proximal cues such as the wall of the pool and an intramaze landmark, appears to ac- quire behavioral control more readily than the place navigation strategy (see also Asem and Holland, 2013). Second, the animals' tendency to use the less preferred place navigation strategy depends upon the relative salience of the proximal and distal cues, a point consistent with many early studies (for review, see Restle 1957) as well as our current results. Our findings add to this existing literature by suggesting that competitive interaction can occur at the level of learning, even when the two strategies are equally relevant (i.e., overshadowing), and that such competition can be eliminated by removing the neural substrate for one of the strategies.

In conclusion, the present study demonstrated that lesions of the DLS impair learning based on a vector from a proximal landmark to the hidden platform near the landmark. This impairment was concomitantly accompanied by a facilitation of an alternative solution of the task, based on the rapid encoding of multiple distal cues, or cognitive mapping. Both of these effects were found only when the distal cues were relatively less salient, indicating the presence of associative competition between learning strategies as an underlying mechanism. The current findings not only reveal an important role of DLS in navigation, but also reveal an important characteristic of interaction between multiple learning systems in the spatial domain.

\section{Materials and Methods}

\section{Experiment 1}

Subjects

The subjects were experimentally naïve male Lister Hooded rats obtained from Charles River, UK. They were $\sim 3$ mo old at the start of the experiment, and were housed in pairs in a temperaturecontrolled room $\left(20^{\circ} \mathrm{C}\right)$ under $12: 12 \mathrm{~h}$ light-dark cycle (lights on at 0700) throughout the experimental period.

\section{Apparatus}

The experiment was conducted in a white pool that was $2 \mathrm{~m}$ in diameter and $60 \mathrm{~cm}$ deep. The pool was filled to a depth of $30 \mathrm{~cm}$ with a mixture of water and white opacifier (OP303B, supplied by Rohm and Haas, UK). This opaque mixture was maintained at a temperature of $25^{\circ} \mathrm{C}\left( \pm 2^{\circ} \mathrm{C}\right)$ and was changed daily. A white circular ceiling with a diameter of $2 \mathrm{~m}$ was suspended 1 $\mathrm{m}$ above the pool. Eight $45-\mathrm{W}$ spotlights were recessed in the ceiling. They were each $22.5 \mathrm{~cm}$ in diameter and arranged symmetrically in a $1 \mathrm{~m}$ circle with its center above the center of the pool. In the center of the circular ceiling was a $30-\mathrm{cm}$ diameter hole into which a wide-angled video camera was fixed. The image from the camera was relayed to a monitor, recording equipment, and a PC. Tracking software (EthoVision, Noldus) was used to record the rats' paths. Outside the pool was an array of visual stimuli attached to or very close to the walls of the room, including various posters and cards with geometric patterns, a boiler, a door, an air conditioner, and a gray curtain drawn back in one corner of the room. Inside the pool, there was a spherical landmark with a diameter of $12 \mathrm{~cm}$, which was painted black on its lower half and white on the upper half. The landmark was mounted on a metal rod, which was fixed to a base resting on the bottom of the pool, so that the entire sphere sat just above the surface of the water. A clear Perspex platform, $10 \mathrm{~cm}$ in diameter and mounted on a $1.5-\mathrm{cm}$ diameter column, was submerged $2 \mathrm{~cm}$ below the surface of the water. The surface of the platform consisted of a series of concentric ridges.

\section{Surgery}

During the surgery, the rats were anaesthetized with a mixture of isoflurane $(1 \%-5 \%)$ and oxygen and placed in a stereotaxic frame (David Kopf Instruments). The incisor bar was set at $-3.3 \mathrm{~mm}$. The scalp was incised at the midline to expose the skull. A dental 
drill was used to remove the skull over the target sites. A 2- $\mu \mathrm{L}$ Hamilton syringe was used to infuse $63 \mathrm{mM}$ ibotenic acid (Tocris Bioscience) dissolved in buffered saline bilaterally into the target region. The coordinates for infusion and the volume of excitotoxin used for the DLS lesions were as follows; AP +1.6 , $\mathrm{ML} \pm 3.0, \mathrm{DV}-4.2(0.25 \mu \mathrm{L}) ; \mathrm{AP}+0.8, \mathrm{ML} \pm 3.7, \mathrm{DV}-4.6$ $(0.25 \mu \mathrm{L}) ; \mathrm{AP}-0.5, \mathrm{ML} \pm 4.5, \mathrm{DV}-4.6(0.25 \mu \mathrm{L})$. The infusion was made with an infusion pump at the rate of $0.03 \mu \mathrm{L} / \mathrm{min}$, and each infusion was followed by a 2 -min diffusion time before the syringe was removed. For the HPC lesions, the coordinates for injections and the volume of each injection followed those described by Jarrard (1989); briefly, the lesion of the whole hippocampus was produced with 28 infusions of ibotenic acid bilaterally.

After the infusions were complete the wound was sutured and the rats were allowed to recover in a warm chamber until conscious. A $10 \mathrm{~mL}$ mixture of glucose and saline was injected subcutaneously after surgery to aid recovery, and buprenorphine $(0.012$ $\mathrm{mg} / \mathrm{kg}$ ) was injected subcutaneously for pain relief.

Sham-operated controls underwent the same surgical procedure with the exception that the Hamilton syringe was not lowered into the brain.

\section{Procedure}

Training. Half of the rats in each group were trained with the platform always positioned $30 \mathrm{~cm}$ due north of the landmark, whereas the other half was trained with the platform $30 \mathrm{~cm}$ due south of the landmark. The distance was taken between the middle of the landmark and the middle of the platform on the same horizontal plane. The position of the landmark-platform unit was constant within a session of four trials, but it moved across sessions over 16 potential different places in the pool. The midpoint of the landmark and the platform was on one of 16 radii, and $50 \mathrm{~cm}$ away from the wall of the pool (see Fig. 1 ). The position of the landmark-platform unit in each session was determined pseudorandomly with a restriction that two neighboring positions were not used in two consecutive sessions.

Each training trial began with the experimenter lowering the rat into the pool, with the rat close to, and facing, the wall. The trial ended when the rat found the submerged platform and climbed onto it, and rested there for 30 sec. If the rat failed to find the platform within $120 \mathrm{sec}$, the experimenter guided the rat to the platform by presenting a finger just in front the animal's snout, after which it was allowed to rest for $30 \mathrm{sec}$ on the platform. After 30 sec on the platform, the rat was picked up, gently dried in a towel, and placed onto a table in the SE corner of the room, where it waited for a further 30 -sec period, after which the same rat was placed in the pool for the next trial.

Each rat received four consecutive trials per session. On each trial, the starting point was chosen randomly from eight possible positions, with a restriction that the potential starting point closest to the landmark-platform array was not used. When testing was finished, the rat was gently dried in a towel and returned to its holding cage.

Landmark test. The rats were trained for 14 sessions, followed by a single landmark test conducted on Day 15. The landmark test was the first and only trial of the day. During the landmark test, the landmark was placed, for the first time, at the center of the pool, and the platform was removed. The rats were released into the pool from the west and allowed to swim for 120 sec. Two notional zones of equal size were set at the north and the south of the platform with their centers being $30 \mathrm{~cm}$ away from the center of the landmark. The two zones were assigned as the correct and incorrect zones according to the direction of the platform assigned for each rat during training. Two behavioral measures were adopted for the analyses: latency to first enter each zone, and the amount of time animals spent searching in each zone. The size of each zone was set at $15 \mathrm{~cm}$ in diameter for the analysis of latency, and $30 \mathrm{~cm}$ in diameter for the analysis of the search time. The smaller zone size for the analysis of latency was used to make the analysis comparable to that in Pearce et al. (1998), in which the platform was actually placed in the original position for half of the rats and in the opposite position for the other half and the latency to find the platform was compared between groups. The rats' swim paths during the test trial were tracked using Ethovision (Version 3.1; Noldus) for subsequent analyses.

Place test. On the next day following the completion of the landmark test, rats received three retraining trials with the landmark and the platform placed at a novel location which, among the 16 possible locations, had never been used during previous training. The three retraining trials were followed by a place test on the fourth trial, during which the intramaze landmark was removed from the pool, so that the animals had to rely on the cues provided by the array of extramaze cues for a successful performance. The platform was also removed from the pool during the test. A notional $30-\mathrm{cm}$ diameter zone was placed with its center coinciding with the place where the platform had been placed during the three preceding trials. A second, equal-sized zone was set at the diametrically opposite position of the pool. The rats were released into the pool from a point equidistant from the two zones and facing the wall of the pool, and allowed to swim for $120 \mathrm{sec}$.

\section{Experiment 2}

The experiment started $\sim 6$ wk after the completion of Experiment 1.

\section{Subjects}

The Sham and DLS rats used in Experiment 1 were used. During the period between the experiments two rats from Sham and one rat from DLS were sacrificed due to ill health conditions, and therefore the final group size was reduced from the last experiment to as follows; Sham, $n=10$; DLS, $n=5$.

\section{Apparatus}

The apparatus was identical to those described for Experiment 1, except that the various room cues were modified and made more salient to provide animals with richer place cues. The modification included the replacement of some of the visual cues on the walls with more prominent cues, and addition of new objects such as a vertical strip of dark blue cloth $(15 \mathrm{~cm} \times 40 \mathrm{~cm}, \mathrm{w} \times \mathrm{h})$ suspended from the ceiling at outside and close to the edge of the pool, and a stand-alone medical screen made of wood $(0.8 \mathrm{~m} \times 1.5 \mathrm{~m}, \mathrm{w} \times \mathrm{h})$ at the periphery of the pool. The surface of the screen was painted with various geometric patterns. In addition, an entire wall to the north of the pool was covered with a black wallpaper except for a vertical gap of $10 \mathrm{~cm}$ in the middle.

\section{Procedure}

The procedure was identical to that for Experiment 1 with the following exceptions. The animals were trained for only six sessions, with six trials per session. The latter change was made as an additional attempt to make the sham animals rely more on the place cues, as inclusion of more trials per session should increase the validity of place cues and reduce the difference between the relative validities of vector and place cues. Following training, a landmark test and a place test were conducted as in the Experiment 1.

\section{Experiment 3}

\section{Subjects}

The subjects were 23, experimentally naïve, male Lister Hooded rats obtained from the same supplier and kept in the same conditions as those for Experiment 1 . They were $\sim 3$ mo old at the start of the experiment. 


\section{Apparatus}

The apparatus was identical to those described for Experiment 2.

\section{Surgery}

The surgical procedure for DLS lesions was identical to that used for Experiment 1.

\section{Procedure}

The training and testing was conducted in a similar manner to Experiment 1, except for the following details. The platform was placed $30 \mathrm{~cm}$ due east of the landmark for half of the subjects in each group, and due west for the other half. The change of goal directions was made in order to prevent animals from using the north black wall as a single cue for navigation (i.e., beacon) and swimming directly toward it. The training consisted of 12 , rather than 14 sessions as training progressed more readily than in Experiment 1.

Conflict test. On the next day following the place test, a conflict test was conducted. After three retraining trials with the landmark and platform in a novel position, the landmark was moved to another novel position which was diametrically opposite to where it had been placed during the three preceding trials. A notional circular zone with a diameter of $30 \mathrm{~cm}$ was set at the location where the platform had been positioned during the last three trials ("place zone"). A second zone of the same size was set at the location where the platform should be expected on the basis of the vector from the current position of the landmark ("landmark zone"), and the times animals spent in these two zones were compared.

\section{Acknowledgments}

This research was supported by grants from the United Kingdom Biotechnology and Biological Sciences Research Council. We are grateful to Heather Crawford and Claire Robinson for assistance in animal husbandry and Andy Long for technical assistance. We thank David Sanderson and John Pearce for their invaluable comments on an earlier version of this manuscript.

\section{References}

Asem JS, Holland PC. 2013. Immediate response strategy and shift to place strategy in submerged T-maze. Behav Neurosci 127: 854-859.

Balleine BW, Dickinson A. 1998. Goal-directed instrumental action: contingency and incentive learning and their cortical substrates Neuropharmacology 37: 407-419.

Blodgett HC, McCutchan K. 1947. Place versus response learning in the simple T-maze. J Exp Psychol 37: 412-422.

Blodgett HC, McCutchan K. 1948. Relative strength of place and response learning in the T maze. J Comp Physiol Psychol 41: 17-24.

Blodgett HC, McCutchan K, Mathews R. 1949. Spatial learning in the T-maze: the influence of direction, turn, and food location. J Exp Psychol 39: 800-809.

Chamizo VD, Manteiga RD, Rodrigo T, Mackintosh NJ. 2006. Competition between landmarks in spatial learning: the role of proximity to the goal. Behav Processes 71: 59-65.

Chang Q, Gold PE. 2003. Intra-hippocampal lidocaine injections impair acquisition of a place task and facilitate acquisition of a response task in rats. Behav Brain Res 144: 19-24.

Chang Q, Gold PE. 2004. Inactivation of dorsolateral striatum impairs acquisition of response learning in cue-deficient, but not cue-available, conditions. Behav Neurosci 118: 383-388.

Cheng K. 1986. A purely geometric module in the rat's spatial representation. Cognition 23: 149-178.

Compton DM. 2004. Behavior strategy learning in rat: effects of lesions of the dorsal striatum or dorsal hippocampus. Behav Processes 67: 335-342.

Devan BD, White NM. 1999. Parallel information processing in the dorsal striatum: relation to hippocampal function. J Neurosci 19: 2789-2798.

Diez-Chamizo V, Sterio D, Mackintosh NJ. 1985. Blocking and overshadowing between intra-maze and extra-maze cues: a test of the independence of locale and guidance learning. Q J Exp Psychol B 37: $235-253$.

Doeller CF, Burgess N. 2008. Distinct error-correcting and incidental learning of location relative to landmarks and boundaries. Proc Natl Acad Sci 105: 5909-5914.

Doeller CF, King JA, Burgess N. 2008. Parallel striatal and hippocampal systems for landmarks and boundaries in spatial memory. Proc Natl Acad Sci 105: 5915-5920.

Gallistel CR. 1990. The organization of learning. MIT Press, Cambridge, MA.

Gibson BM, Shettleworth SJ. 2005. Place versus response learning revisited: tests of blocking on the radial maze. Behav Neurosci 119: 567-586.

Hamilton DA, Akers KG, Weisend MP, Sutherland RJ. 2007. How do room and apparatus cues control navigation in the Morris water task? Evidence for distinct contributions to a movement vector. J Exp Psychol Anim Behav Process 33: 100-114.

Hamilton DA, Akers KG, Johnson TE, Rice JP, Candelaria FT, Sutherland RJ, Weisend MP, Redhead ES. 2008. The relative influence of place and direction in the Morris water task. J Exp Psychol Anim Behav Process 34: $31-53$.

Hamilton DA, Akers KG, Johnson TE, Rice JP, Candelaria FT, Redhead ES. 2009. Evidence for a shift from place navigation to directional responding in one variant of the Morris water task. J Exp Psychol Anim Behav Process 35: 271-278.

Horne MR, Pearce JM. 2011. Potentiation and overshadowing between landmarks and environmental geometric cues. Learn Behav 39: $371-382$.

Horne MR, Iordanova MD, Pearce JM. 2010. Spatial learning based on boundaries in rats is hippocampus-dependent and prone to overshadowing. Behav Neurosci 124: 623-632.

Jarrard LE. 1989. On the use of ibotenic acid to lesion selectively different components of the hippocampal formation. J Neurosci Methods 29: 251-259.

Kamin LJ. 1969. Predictability, surprise, attention, and conditioning. In Punishment and aversive behavior (ed. Campbell BA, Church RM), pp. 279-296. Appleton-Century-Crofts, New York.

Killcross S, Coutureau E. 2003. Coordination of actions and habits in the medial prefrontal cortex of rats. Cereb Cortex 13: 400-408.

Kim JJ, Lee HJ, Han JS, Packard MG. 2001. Amygdala is critical for stress-induced modulation of hippocampal long-term potentiation and learning. J Neurosci 21: 5222-5228.

Kosaki Y, Austen JM, McGregor A. 2013. Overshadowing of geometry learning by discrete landmarks in the water maze: effects of relative salience and relative validity of competing cues. J Exp Psychol Anim Behav Process 39: 126-139.

Lee AS, Duman RS, Pittenger C. 2008. A double dissociation revealing bidirectional competition between striatum and hippocampus during learning. Proc Natl Acad Sci 105: 17163-17168.

Mackintosh NJ. 1975. A theory of attention: variations in the associability of stimuli with reinforcement. Psychol Rev 82: 276-298.

Mackintosh NJ. 1976. Overshadowing and stimulus intensity. Anim Learn Behav 4: 186-192.

McDonald RJ, White NM. 1993. A triple dissociation of memory systems: hippocampus, amygdala, and dorsal striatum. Behav Neurosci 107: $3-22$.

McNamara HJ, Long JB, Wike EL. 1956. Learning without response under two conditions of external cues. J Comp Physiol Psychol 49: 477-480.

Miles CG, Jenkins HM. 1973. Overshadowing in operant conditioning as a function of discriminability. Learn Motiv 4: 11-27.

Mitchell JA, Hall G. 1988. Caudate-putamen lesions in the rat may impair or potentiate maze learning depending upon availability of stimulus cues and relevance of response cues. QJ Exp Psychol B 40: 243-258.

Morris RG, Garrud P, Rawlins JN, O'Keefe J. 1982. Place navigation impaired in rats with hippocampal lesions. Nature 297: 681-683.

O'Keefe J, Nadel L. 1978. The hippocampus as a cognitive map. Clarendon Press, Oxford, UK.

Oswald CJ, Bannerman DM, Yee BK, Rawlins JN, Honey RC, Good M. 2003. Entorhinal cortex lesions disrupt the transition between the use of intra- and extramaze cues for navigation in the water maze. Behav Neurosci 117: 588-595.

Packard MG, Goodman J. 2013. Factors that influence the relative use of multiple memory systems. Hippocampus 23: 1044-1052.

Packard MG, McGaugh JL. 1992. Double dissociation of fornix and caudate nucleus lesions on acquisition of two water maze tasks: further evidence for multiple memory systems. Behav Neurosci 106: 439-446.

Packard MG, McGaugh JL. 1996. Inactivation of hippocampus or caudate nucleus with lidocaine differentially affects expression of place and response learning. Neurobiol Learn Mem 65: 65-72.

Packard MG, Hirsh R, White NM. 1989. Differential effects of fornix and caudate nucleus lesions on two radial maze tasks: evidence for multiple memory systems. J Neurosci 9: 1465-1472.

Pavlov IP. 1927. Conditioned reflexes. Oxford University Press, London. 
Paxinos G, Watson C. 1998. The rat brain in stereotaxic coordinates, 4th ed. Academic Press, San Diego, CA.

Pearce JM. 2009. The 36th Sir Frederick Bartlett lecture: an associative analysis of spatial learning. Q J Exp Psychol 62: 1665-1684.

Pearce JM, Hall G. 1980. A model for Pavlovian learning: variations in the effectiveness of conditioned but not of unconditioned stimuli. Psychol $\operatorname{Rev}$ 87: 532-552.

Pearce JM, Roberts AD, Good M. 1998. Hippocampal lesions disrupt navigation based on cognitive maps but not heading vectors. Nature 396: $75-77$.

Pearce JM, Graham M, Good MA, Jones PM, McGregor A. 2006. Potentiation, overshadowing, and blocking of spatial learning based on the shape of the environment. J Exp Psychol Anim Behav Process 32: 201-214.

Poldrack RA, Clark J, Paré-Blagoev EJ, Shohamy D, Creso Moyano J, Myers C, Gluck MA. 2001. Interactive memory systems in the human brain. Nature 414: 546-550.

Pych JC, Chang Q, Colon-Rivera C, Haag R, Gold PE. 2005. Acetylcholine release in the hippocampus and striatum during place and response training. Learn Mem 12: $564-572$.

Redhead ES, Roberts A, Good M, Pearce JM. 1997. Interaction between piloting and beacon homing by rats in a swimming pool. J Exp Psychol 23: $340-350$.

Rescorla RA, Wagner AR. 1972. A theory of Pavlovian conditioning: variations in the effectiveness of reinforcement and nonreinforcement. In Classical conditioning II: current theory and research (ed. Black AH, Prokasy WF), pp. 64-99. Appleton-Century-Crofts, New York.

Restle F. 1957. Discrimination of cues in mazes: a resolution of the place-vs.-response question. Psychol Rev 64: 217-228.

Roberts AD, Pearce JM. 1998. Control of spatial behavior by an unstable landmark. J Exp Psychol Anim Behav Process 24: 172-184.
Roberts AD, Pearce JM. 1999. Blocking in the Morris swimming pool. J Exp Psychol 25: 225-235.

Schwabe L, Dalm S, Schächinger H, Oitzl MS. 2008. Chronic stress modulates the use of spatial and stimulus-response learning strategies in mice and man. Neurobiol Learn Mem 90: 495-503.

Skinner DM, Etchegary CM, Ekert-Maret EC, Baker CJ, Harley CW, Evans JH, Martin GM. 2003. An analysis of response, direction, and place learning in an open field and T maze. J Exp Psychol Anim Behav Process 29: 3-13.

Tolman EC, Ritchie BF, Kalish D. 1947. Studies in spatial learning. IV. The transfer of place learning to other starting paths. J Exp Psychol 37: $39-47$.

Vann SD, Aggleton JP. 2004. Testing the importance of the retrosplenial guidance system: effects of different sized retrosplenial cortex lesions on heading direction and spatial working memory. Behav Brain Res 155: 97-108.

Wagner AR, Logan FA, Haberlandt K, Price T. 1968. Stimulus selection in animal discrimination learning. J Exp Psychol 76: 171-180.

White NM. 2005. How independent are parallel memory systems? A theoretical comment on Gibson and Shettleworth (2005). Behav Neurosci 119: 1158-1164.

Wiener SI. 1993. Spatial and behavioral correlates of striatal neurons in rats performing a self-initiated navigation task. J Neurosci 13: 3802-3817.

Yin HH, Knowlton BJ, Balleine BW. 2004. Lesions of dorsolateral striatum preserve outcome expectancy but disrupt habit formation in instrumental learning. Eur J Neurosci 19: 181-189.

Received September 21, 2014; accepted in revised form November 26, 2014. 


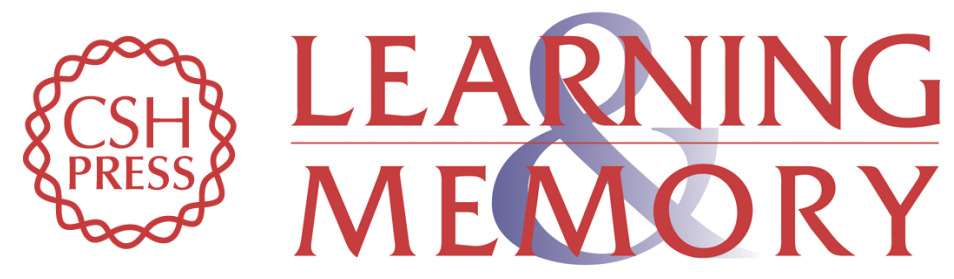

\section{Dorsolateral striatal lesions impair navigation based on landmark-goal vectors but facilitate spatial learning based on a "cognitive map"}

Yutaka Kosaki, Steven L. Poulter, Joe M. Austen, et al.

Learn. Mem. 2015, 22:

Access the most recent version at doi:10.1101//m.037077.114

References This article cites 55 articles, 8 of which can be accessed free at: http://learnmem.cshlp.org/content/22/3/179.full.html\#ref-list-1

Creative This article is distributed exclusively by Cold Spring Harbor Laboratory Press for the Commons first 12 months after the full-issue publication date (see

License http://learnmem.cshlp.org/site/misc/terms.xhtml). After 12 months, it is available under a Creative Commons License (Attribution-NonCommercial 4.0 International), as described at http://creativecommons.org/licenses/by-nc/4.0/.

Email Alerting Receive free email alerts when new articles cite this article - sign up in the box at the Service top right corner of the article or click here. 